Research Article

\title{
Experimental Study on High-Cycle Fatigue Behavior of GFRP-Steel Sleeve Composite Cross Arms
}

\author{
Jiantao Wang $\mathbb{D}^{1},{ }^{1}$ Ning Tan, ${ }^{2}$ Shiming Zhou, ${ }^{1}$ and Qing Sun ${ }^{1}{ }^{1}$ \\ ${ }^{1}$ Department of Civil Engineering, Xi'an Jiaotong University, Xi'an, Shaanxi 710049, China \\ ${ }^{2}$ School of Aerospace, Xi'an Jiaotong University, Xi'an, Shaanxi 710049, China \\ Correspondence should be addressed to Qing Sun; sunq@mail.xjtu.edu.cn
}

Received 19 March 2018; Revised 5 July 2018; Accepted 16 July 2018; Published 1 August 2018

Academic Editor: Flavio Stochino

Copyright ( 2018 Jiantao Wang et al. This is an open access article distributed under the Creative Commons Attribution License, which permits unrestricted use, distribution, and reproduction in any medium, provided the original work is properly cited.

To overcome the fatigue safety problem of transmission tower cross arms caused by the wind-induced vibrations, an experimental study on the high-cycle fatigue performance of a new type of GFRP-steel sleeve composite cross arms was carried out. A total of six specimens were subjected to 500 thousand cyclic loadings based on the practical engineering background. The stress state was monitored, and a variety of load-displacement-time curves, the energy dissipation capacity, and the dynamic strain were analyzed to examine the effects of fatigue loading. After the fatigue test, the specimens without significant fatigue failure were evaluated to derive the residual bearing capacity. Based on the residual strength theory, the cumulative damage was examined, and the fatigue life was predicted under various loading conditions to ensure the reliability of composite cross arms. It is shown that the new type full-scale GFRP-steel sleeve composite cross arms can demonstrate a high level of safety redundancy on antifatigue performance and can be expected for wide application in power transmission towers.

\section{Introduction}

Glass-fiber-reinforced polymers (GFRPs) have been applied in manufacturing power transmission engineering widely as a replacement of conventional materials (wood, concrete, and steel) because of its unique advantages of high strength-toweight ratio, resistance to corrosion, lower transportation, and installation and maintenance costs $[1,2]$. Adopting GFRP cross arm in transmission tower can improve the reliability of power supply through reducing the negative effects of partial discharge and contamination flashover, while it can obtain the significant economic benefits by reducing the width of the transmission line corridor and maintenance costs. However, the fatigue load of GFRP cross arms caused by wind-induced vibrations is a safety problem that cannot be neglected in the design period $[3,4]$. Actually, fatigue failure is one of the most important failure types of GFRPs during their service. Due to the inhomogeneity and anisotropy, the fatigue failure mechanisms of fiber-reinforced composites are vastly different from their counterparts in homogeneous and isotropic materials, like metals [5]. Furthermore, structural components are usually subjected to complex fatigue loadings, which is one of the main forms of failure in mechanic and structural catastrophes. The GFRP cross arms are exposed to complex stress conditions (like wind oscillation). Once the fatigue failure occurs, it can result in major direct and indirect consequences on the economy and national security. Therefore, it is of great importance to examine the fatigue behavior of GFRP cross arms to ensure the safety of transmission towers.

During the past decades, many scholars have studied the fatigue problem of composite materials to the different extent, such as fatigue mechanics behavior, residual strength, and fatigue life prediction [5-26]. For instance, Hashin and Rotem $[5,8]$ developed a fatigue failure theory based on the Hashin-Rotem static failure criterion, which has been applied to predict the fatigue failure of angle-ply laminates. Yang et al. [9] and Shokrieh and Taheri-Behrooz [12] proposed methods of fatigue life prediction based on the modulus reduction and energy dissipation, respectively. Abo-Elkhier et al. [17] investigated the fatigue life of GFRP composites using modal testing, which indicates that the 
changes of modal parameters provide a proper method for predicting the fatigue behavior of composite structures. Zhang et al. [22] proposed a macrophenomenological fatigue model for the off-axis fatigue behavior of GFRP composite laminates. However, the aforementioned researches about the fatigue properties of composite materials mainly concentrate on the material level and reduced scale members, especially for the cumulative damage assessment and fatigue life prediction. So far, studies on high-cycle fatigue behavior of GFRP based on full-scale components are found lacking. Therefore, it is necessary to carry out experimental researches on high-cycle fatigue performance about the full-scale GFRP components, considering the influence of size effect on composite material defects.

In this paper, an experimental study on high-cycle fatigue properties of a new type of full-scale GFRP-steel sleeve composite cross arms was conducted. A total of six specimens were subjected to 500 thousand cyclic loadings. The stress state, load-displacement-time curve, energy dissipation capacity, and dynamic strain were analyzed in detail. The ultimate bearing capacity of the specimens was evaluated to derive residual bearing capacity. Based on the modified residual strength theory, the cumulative damage was assessed to predict the fatigue life of GFRP-steel sleeve composite cross arms.

\section{Experiment Condition}

2.1. Specimen Details. In this study, a total of six standard specimens were designed and produced by Jiangsu Shemar Electric Co., Ltd. All the GFRP pipes with steel sleeves (steel grade Q345) spliced on both ends were manufactured through the filament winding process. A total of thirty fiber layers, divided into ten fixed skeleton layers and twenty variable angle layers, were winded in a constant thickness of $0.66 \mathrm{~mm}$ per layer, where the inside-out layout was $90^{\circ} / 2(\mathrm{~S})$ $60^{\circ} / 2(\mathrm{~S})-30^{\circ} / 8(\mathrm{~V})-90^{\circ} / 2(\mathrm{~S})-30^{\circ} / 8(\mathrm{~V})-90^{\circ} / 2(\mathrm{~S})-30^{\circ} / 4(\mathrm{~V})-$ $60^{\circ} / 2(\mathrm{~S})$. In the notation adopted to identify the fiber layers aforesaid, the first number denoted winding angles between the fiber orientation and axis; the second number denoted the sums of winding fiber layers; the letters " $S$ " and " $V$ " denoted the fixed skeleton layer and variable angle layer, respectively. The specimen size and arrangement of measuring points are shown in Figure 1, in which the composite cross arm was $2532 \mathrm{~mm}$ long and the length of steel sleeve was $466 \mathrm{~mm}$. The outer diameter and wall thickness of the composite pipe were $461 \mathrm{~mm}$ and $20 \mathrm{~mm}$, respectively. Sixteen stiffening ribs were welded along the perimeter of the steel sleeve, for which the wall thickness and outer diameter were $16 \mathrm{~mm}$ and $600 \mathrm{~mm}$, respectively. In order to monitor the deformation of the specimen during the fatigue test, the locations of the strain gauges in this fatigue test were mainly mounted on the loading ends, which were sensitive to fatigue loads. Four strain gauges in the first row, including two biaxial strain gauges and two unidirectional strain gauges, were arranged in an interval of $90^{\circ}$ along the circumferential direction. Two biaxial strain gauges were mounted by the symmetrical layout in the other rows.
2.2. Loading Scheme. In this paper, based on the XimengShengli section ultrahigh voltage (UHV) transmission project in China, the finite element method was first employed to carry out the dynamic time-history analysis for determining fatigue peak loads of the experiment. The accuracy and validity of this finite element method were verified by Northwest Electric Power Design Institute Co., Ltd. of China Power Engineering Consulting Group. The internal forces of the transmission tower cross arms at the basic wind speed of $10 \mathrm{~m} / \mathrm{s}$ and strong wind speed of $30 \mathrm{~m} / \mathrm{s}$ were extracted as the basic and ultimate reference loading conditions, respectively. The practical UHV transmission towers located in Xilin Gol League of China were subjected to the adverse wind-induced vibrations. Therefore, through the statistic of the local climate condition, the 500,000 times high-cycle fatigue loading was determined to simulate the actual stress state in life cycle at different safety margins based on the design requirement, namely, for the GFRP composite cross arms of the UHV transmission towers, fatigue failure cannot occur at the basic frequent design wind speed $(10 \mathrm{~m} / \mathrm{s})$ and extremely infrequent ultimate wind speed $(30 \mathrm{~m} / \mathrm{s})$, respectively. Further, if there was no evident fatigue failure occurred during the aforesaid conditions, the more adverse loading protocols about the equal amplitudes of tension-compression were determined to examine the different safety margins based on the ultimate reference loading conditions $(30 \mathrm{~m} / \mathrm{s})$ for further reliability. The fatigue test was carried out by the MTS244.31 hydraulic servo actuation system. The loading scheme based on the dynamic analysis result is shown in Table 1.

As is shown in Table 1, the fatigue cycle load was applied at $1 \mathrm{~Hz}$ frequency using the displacement control. After the test, ultimate bearing capacity of the specimens without significant fatigue failure was evaluated to derive residual bearing capacity using the Tianshui-Hongshan $20,000 \mathrm{kN}$ computer-controlled electrohydraulic servo pressure and shear testing machine. The loading device of the high-cycle fatigue test and ultimate bearing capacity test is shown in Figure 2. For comparison, three standard composite cross arms from the same batch were tested to obtain the original no-fatigue compressive bearing capacity before the residual bearing capacity experiment.

\section{Test Results and Analysis}

3.1. Failure Mode. After the test, the summary of test results is shown in Table 2, in which there was no significant fatigue failure occurred of GFRP-steel composite cross arms during the 500 thousand high-cycle fatigue test. Then, the axial compression test was carried out to derive the residual ultimate bearing capacity of the specimens. A summary of the failure modes is shown in Figure 3, from which the severe shear failures appeared in the composite material portion. All the tested specimens demonstrated the similar failure modes after the residual bearing capacity test. Taking the specimen GZ-5 as an example, the last two photos in Figure 3 indicate that the ultimate bearing capacity was reached as the layered fibers broke from the resin accompanied by a huge "bang" simultaneously. Moreover, the specimen test 


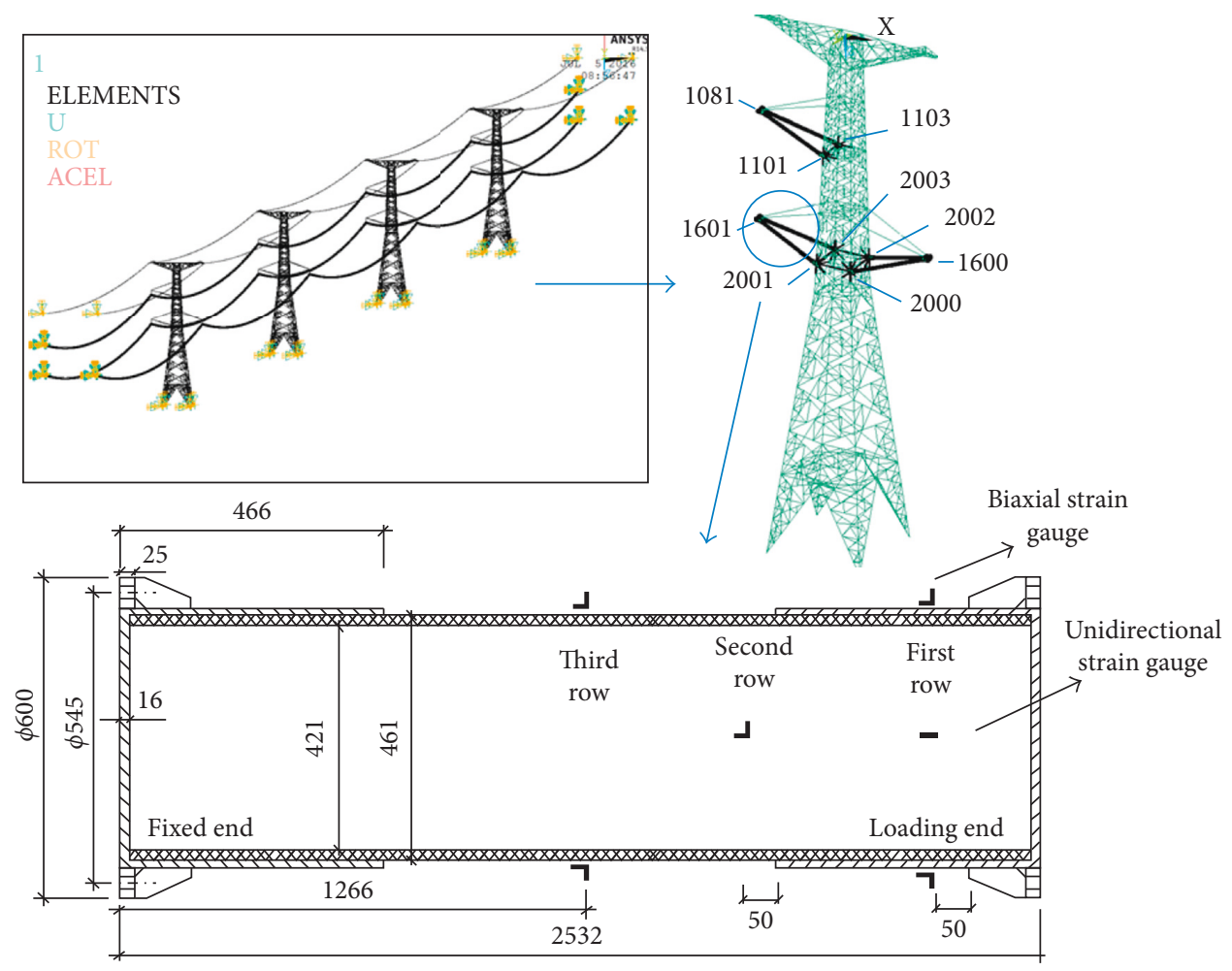

Figure 1: The specimen size and arrangement of measuring points.

TABLE 1: Loading scheme.

\begin{tabular}{|c|c|c|c|c|c|}
\hline \multirow{2}{*}{ Specimen } & \multirow{2}{*}{ Loading condition } & \multicolumn{2}{|c|}{ Load peak $(\mathrm{kN})$} & \multirow{2}{*}{ Cycles } & \multirow{2}{*}{ Comments } \\
\hline & & Upper limit & Lower limit & & \\
\hline GZ-1 & 1 & 97.88 & 43.63 & 500,000 & Basic windy condition: $10 \mathrm{~m} / \mathrm{s}$ \\
\hline GZ-2 & 1 & 97.88 & 43.63 & 500,000 & Basic windy condition: $10 \mathrm{~m} / \mathrm{s}$ \\
\hline GZ-3 & 2 & 178.98 & -40.96 & 500,000 & Ultimate windy condition: $30 \mathrm{~m} / \mathrm{s}$ \\
\hline GZ-4 & 3 & 178.98 & -178.98 & 500,000 & Equal amplitudes of tension-compression loading \\
\hline GZ-5 & 4 & 200.00 & -200.00 & 500,000 & 1.1 times of loading condition 3 \\
\hline GZ-6 & 5 & 230.00 & -230.00 & 500,000 & 1.3 times of loading condition 3 \\
\hline
\end{tabular}

Negative sign of the load peak indicates tension loads, while positive sign indicates compression loads.

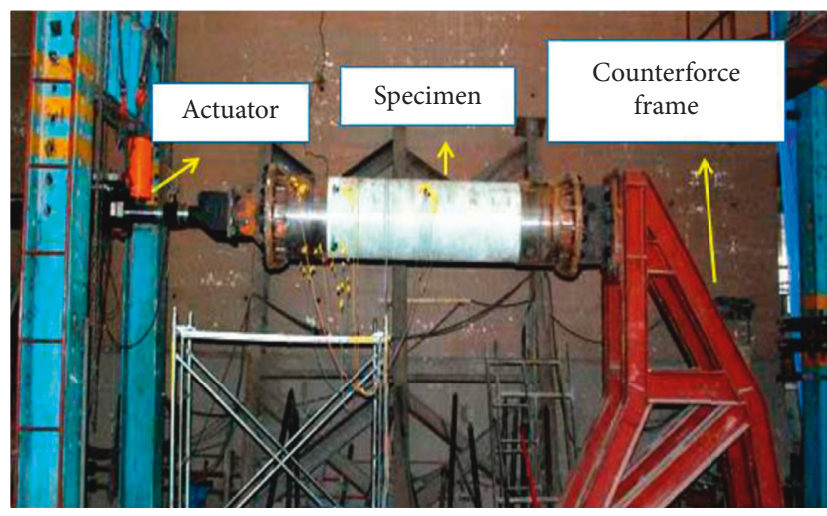

(a)

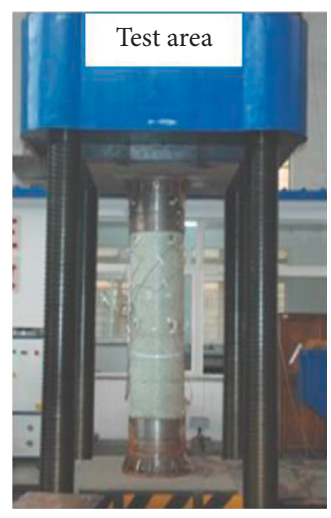

(b)

Figure 2: Test devices: (a) high-cycle fatigue test; (b) ultimate bearing capacity test. 
TABLE 2: Summary of test results.

\begin{tabular}{lllc}
\hline Specimen & \multicolumn{1}{c}{ Test phenomenon } & Failure test & Residual ultimate bearing capacity (kN) \\
\hline GZ-1 & No significant fatigue failure phenomenon & Axial compression & 5,850 \\
GZ-2 & No significant fatigue failure phenomenon & Axial compression & 5,825 \\
GZ-3 & No significant fatigue failure phenomenon & Axial compression & 5,891 \\
GZ-4 & No significant fatigue failure phenomenon & Axial compression & 6,304 \\
GZ-5 & No significant fatigue failure phenomenon & Axial compression & 5,617 \\
GZ-6 & No significant fatigue failure phenomenon & Axial compression & 5,566 \\
\hline
\end{tabular}

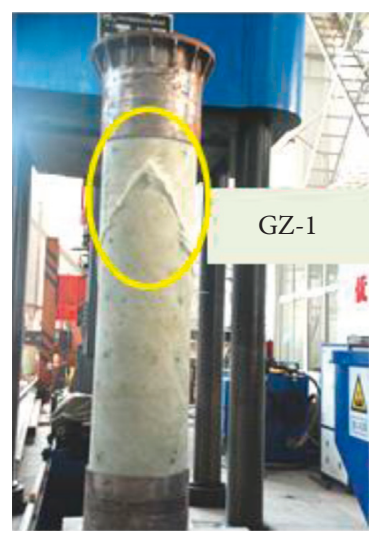

(a)

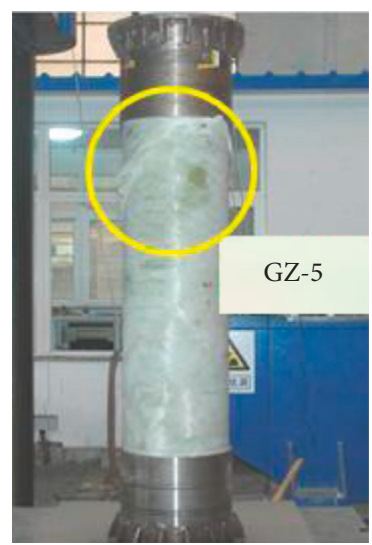

(e)

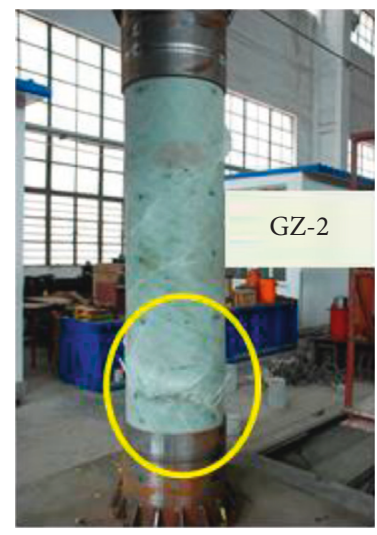

(b)

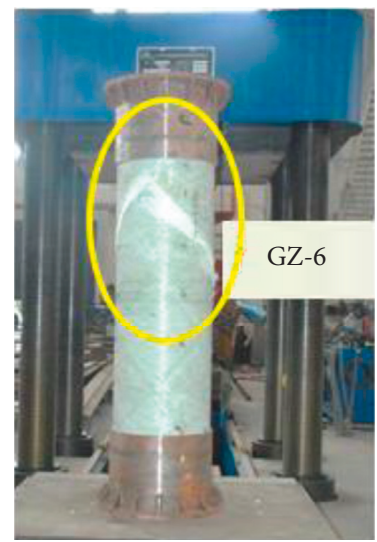

(f)

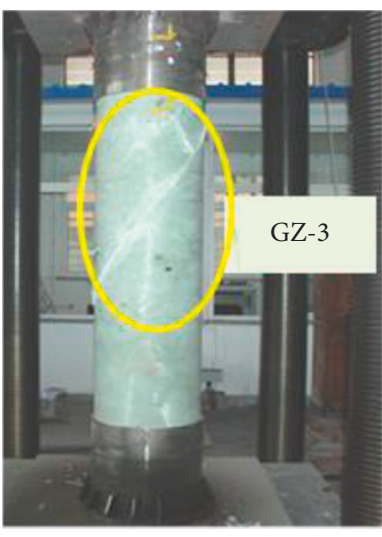

(c)

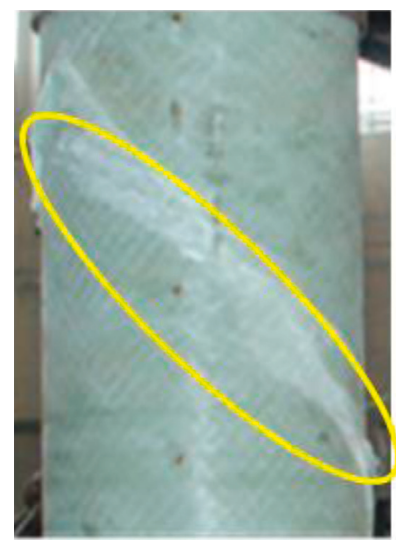

(g)

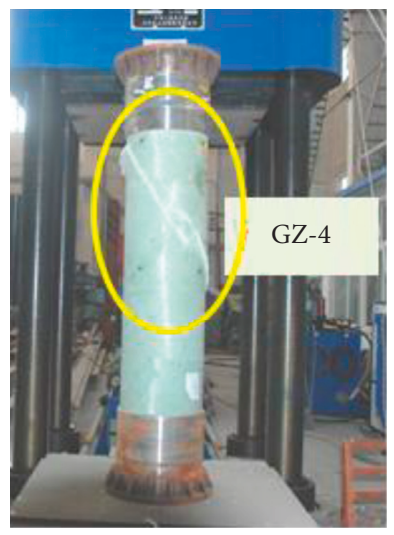

(d)

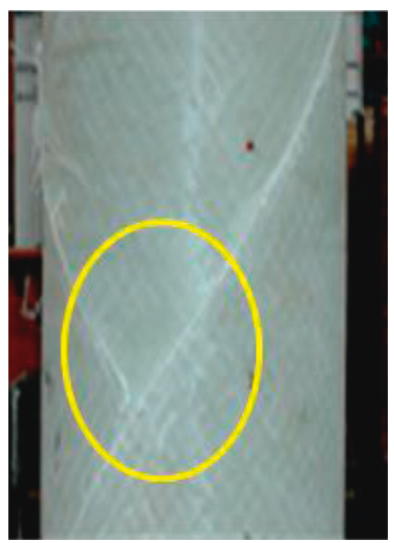

(h)

Figure 3: Typical shear failure mode.

(like the coupon test) was conducted to obtain the original no-fatigue compressive bearing capacity, in which the original average compressive bearing capacity was $6,472 \mathrm{kN}$. The failure modes of the no-fatigue specimen test were similar to those specimens with fatigue loading.

\subsection{Load-Displacement-Time Curves. A variety of me-} chanical properties of GFRP cross arms can be monitored by load-displacement-time curves during the fatigue test. Due to the page limitations, the GZ-6 specimen under the most unfavourable loading condition 5 was taken as an example to illustrate the response of the GFRP-steel sleeve composite cross arms.

The load-displacement-time curve of the GZ-6 specimen is shown in Figure 4. It can be seen that the load peak and valley of the specimen were stable during the fatigue test, which was consistent with the preset value of the loading scheme. Compared with the load-displacement-time curves and test results of the other specimens, it indicates that the GFRP cross arm has good workability after 500,000 times of high-cycle fatigue load without obvious fatigue failure phenomenon based on the macrophenomenon.

3.3. Energy Dissipation. Based on the energy analysis, the load-displacement data of five cycles were fitted at the loading times of 100,000, 200,000,300,000,400,000, and 500,000 seconds nearby. The energy dissipation of different monitoring nodes, namely, the area of the load-displacement hysteresis loop, could be calculated by the numerical integration [27-29], and the changes of mechanical properties 


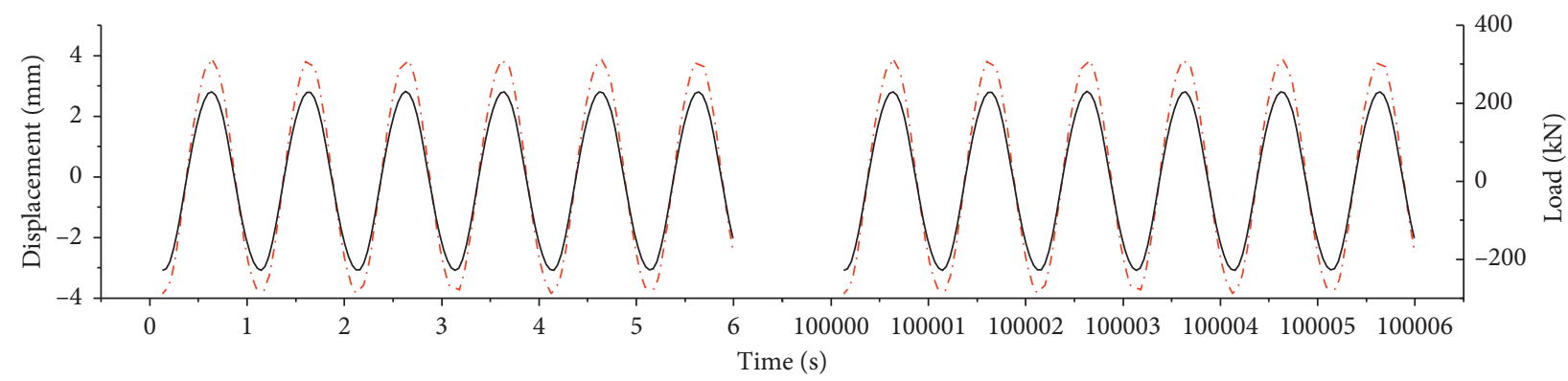

(a)

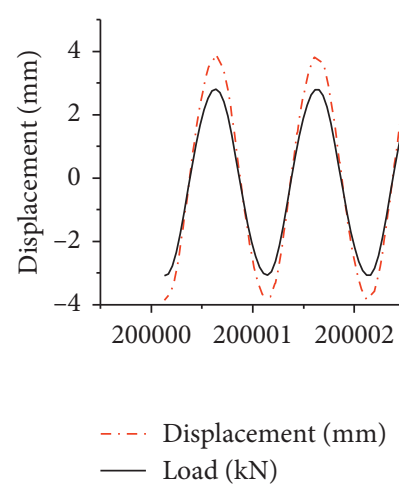

(b)

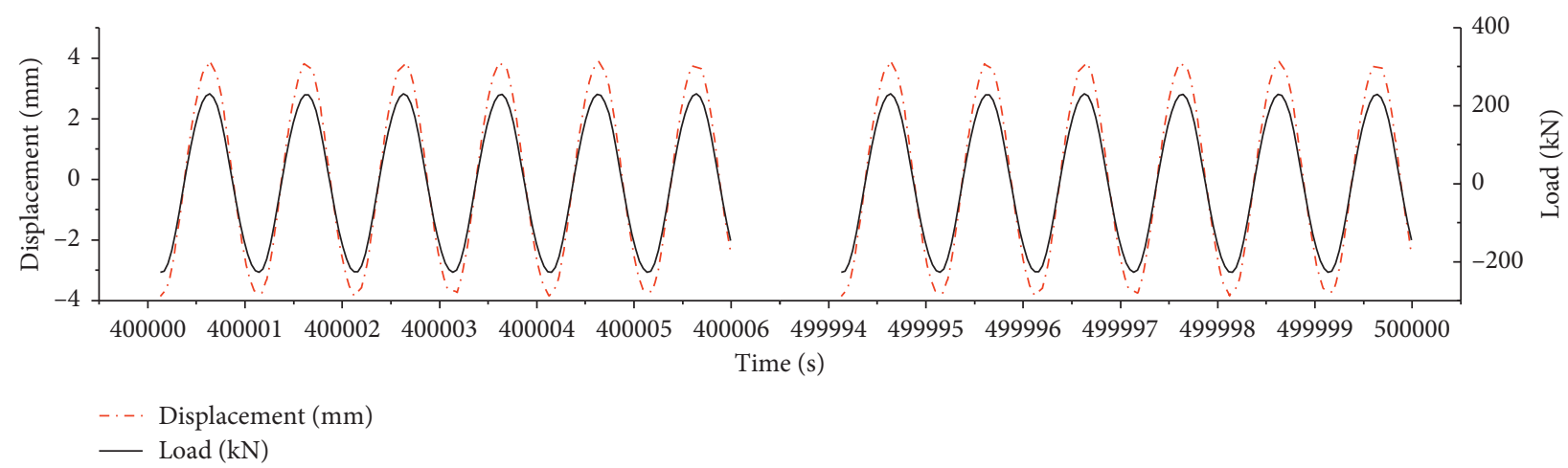

(c)

Figure 4: Analysis of the GZ-6 load-displacement-time curve.

and development of cumulative damage were investigated through energy dissipation analysis shown in Figure 5.

Figure 5 provides the energy dissipation analysis of the corresponding monitoring points of the specimens. The results indicated that the energy consumption values of GZ1, GZ-2, and GZ-4 specimens increased before 300,000 cycles, and values of GZ-3, GZ-5, and GZ-6 increased before 200,000 cycles. Then, the energy dissipation values decreased slowly. It is shown that the microcracks grew constantly in composite materials until the stable state, and then the stiffness degenerated gradually with an increase in the cumulative damage, which could be observed by the variation in energy dissipation. Due to the first transcendental damage caused by the anisotropy of composite and the increase of fatigue loads, the attenuation of energy dissipation values of
GZ-3, GZ-5, and GZ-6 was advanced. Moreover, in the later stage, the cumulative damage developed gradually and the energy dissipation values decreased to a lesser extent.

The typical energy dissipation loop of each specimen is shown in Figure 6, taking the GZ-6 specimen as an example, from which a long "needle" loop could be observed, and the degradation phenomenon of the specimen under high-cycle fatigue loads was not obvious. It reflected that the GFRP cross arms still worked in the elastic stage, and the cumulative residual microplastic deformation was tiny.

3.4. Strain Analysis. In this part, the dynamic strain during fatigue loading and the static strain during the ultimate bearing capacity test were monitored to evaluate the negative effects caused by fatigue loads on the GFRP cross arms. 


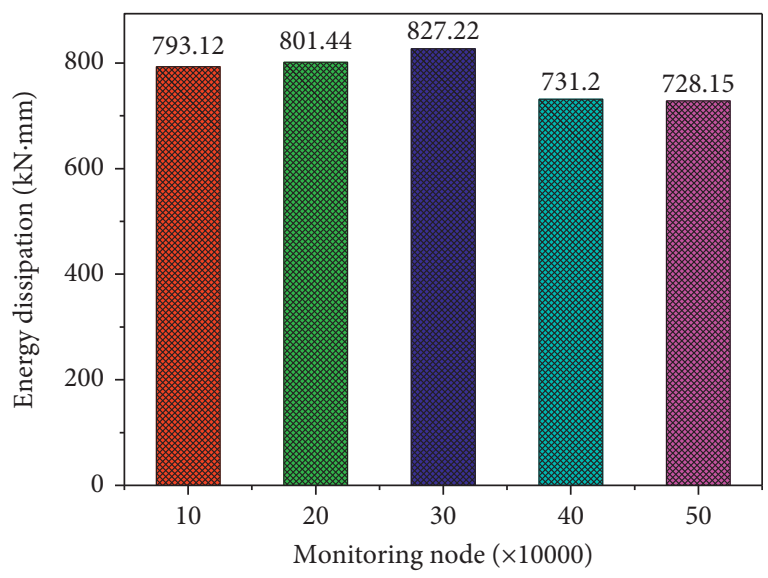

(a)

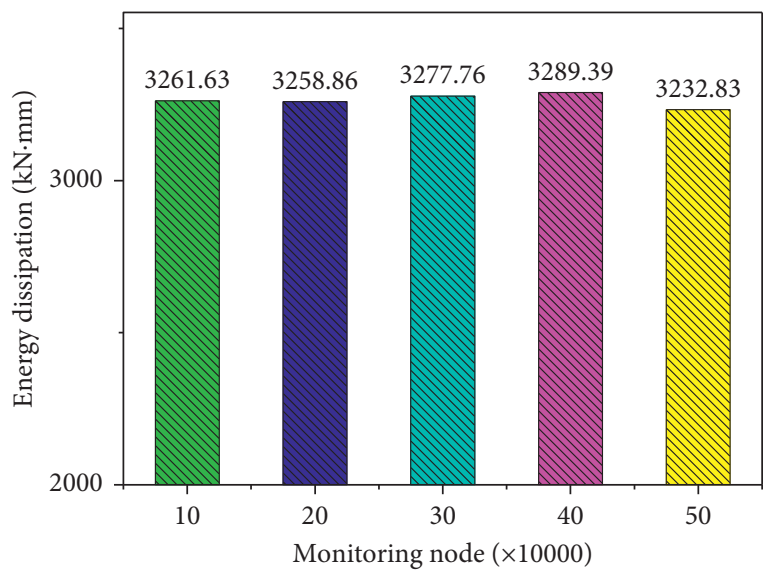

(c)

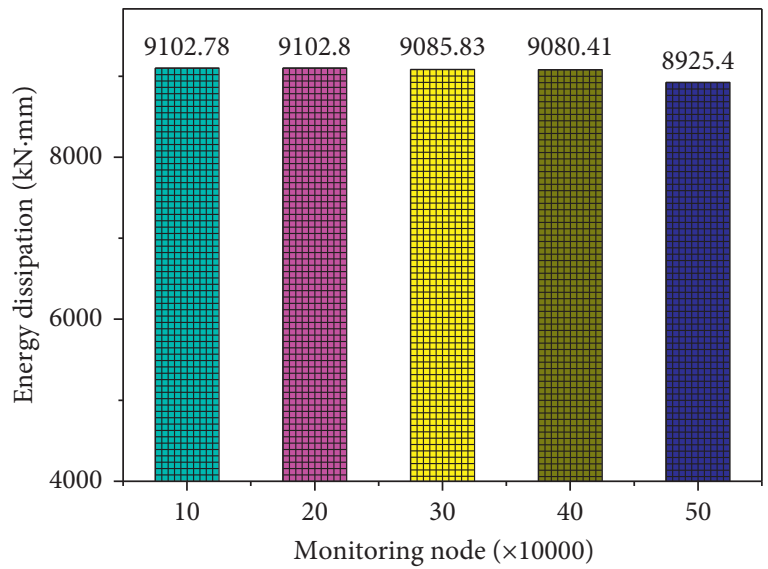

(e)

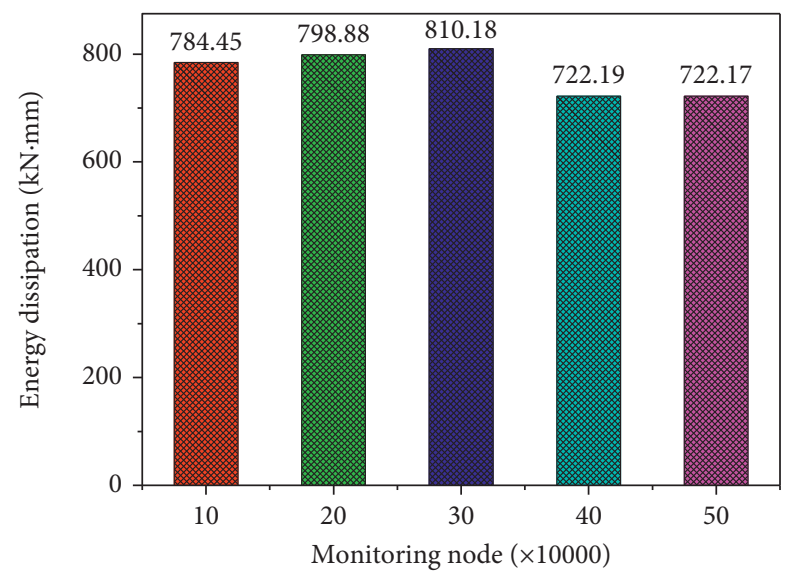

(b)

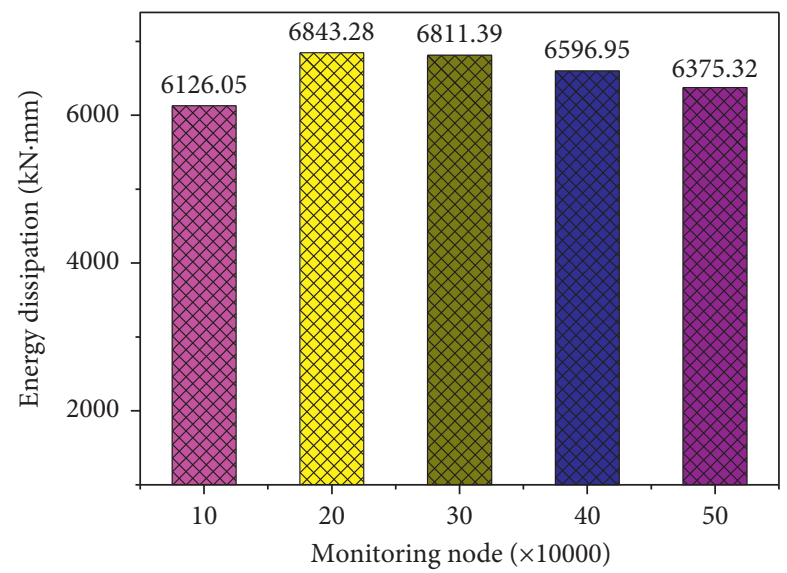

(d)

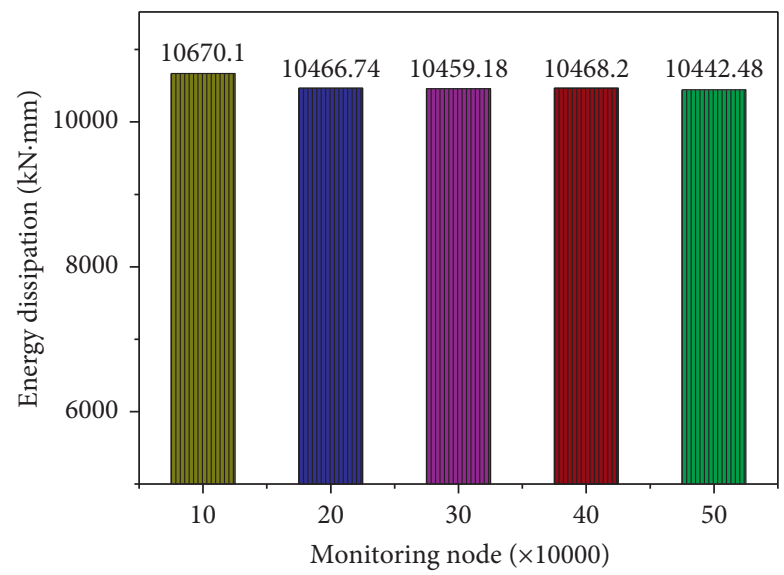

(f)

FIgUre 5: Energy dissipation analysis: (a) GZ-1; (b) GZ-2; (c) GZ-3; (d) GZ-4; (e) GZ-5; (f) GZ-6.

3.4.1. Dynamic Strain. In the process of the high-cycle fatigue test, in order to monitor the deformation and stress state of the specimens, especially the composite material part, the dynamic strain gauges were employed to monitor the variety of deformation. The specimen GZ-1 with minimum fatigue load and the GZ-6 specimen with the maximum fatigue load were taken as examples to analyze the dynamic strain value near the nodes of 500,000 cycles, where the numerals 2-1 and 3-1 denote the longitudinal strain at the first row of the composite material section; 2-2 and 3-2 denote the circumferential strain at the first row of the composite material section. The dynamic strain is shown in Figure 7.

Figures 7 (a) and 7 (b) are the dynamic strain graphs of the specimen GZ-1 under condition 1 and the specimen GZ6 under condition 5. It can be seen that the strain value of the 


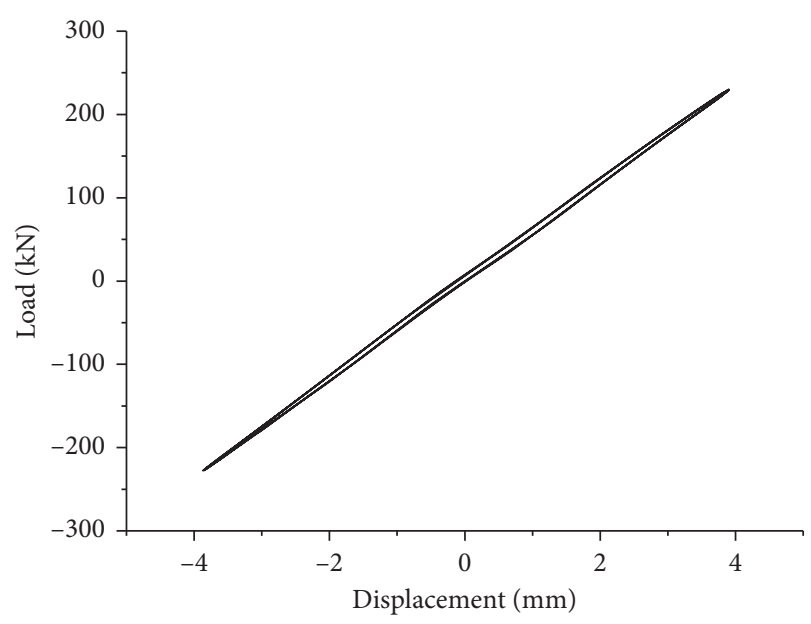

FIgURE 6: Typical energy dissipation loop.

GZ-1 specimen was tiny when subjected to high-cycle fatigue loading, where it had a maximum peak strain of $30 \mu \varepsilon$ in longitudinal compression and $30 \mu \varepsilon$ in circumferential tension, respectively. Apparently, under the most adverse condition 5, the longitudinal and circumferential peak strain of the specimen GZ-6 were about $200 \mu \varepsilon$ and $400 \mu \varepsilon$, respectively, while the relative longitudinal amplitude was about $600 \mu \varepsilon$, which indicated that fatigue loads had slight impact on the deformation capacity of GFRP cross arms. On the whole, the specimens were basically in the elastic working state.

3.4.2. Static Strain. During the residual ultimate bearing capacity test, the strain of GZ-6 (taking as an example) was monitored as shown in Figure 8. Compared to the dynamic strain in Figure 7, an unconspicuous nonlinear relationship could be observed until the specimens failed, and the final strain was obviously greater than its dynamic strain. There were some differences in the static strain because of the anisotropic nature of the composites, but the overall variation was consistent. The ultimate strain of longitudinal and circumferential directions reached up to $12000 \mu \varepsilon$ and $7000 \mu \varepsilon$, respectively. After the high-cycle fatigue loads, the GFRP composite cross arms could demonstrate favourable antideformation ability.

3.5. Residual Ultimate Bearing Capacity. After the fatigue test, the ultimate bearing capacity of specimens was analyzed to examine the adverse impact of fatigue loads. Figure 9 describes the variety of load-displacement curves after the fatigue test. It indicated that the loads had an approximately linear increase with the increment in displacement, and then a sudden drop occurred as the ultimate bearing capacity was reached. Compared to the original average no-fatigue compressive bearing capacity of $6,472 \mathrm{kN}$, the average residual ultimate bearing capacity after the fatigue test was $5,842.17 \mathrm{kN}$. It indicated that the whole GFRP cross arms, subjected to 500 thousand cycles fatigue loads, had an obvious decrease $(9.73 \%)$ in ultimate bearing capacity. This could provide basic references for the cumulative damage evaluation and fatigue life prediction based on the macroscopic phenomenon. From GZ-1 to GZ-6, it can be seen that the ultimate bearing capacity of GZ-6 decreased at a maximum extent of $14.00 \%$ and GZ-4 reduced to a minimum degree of $2.60 \%$. It should be noted that the maximum and minimum cyclic loading levels of GZ-6 and GZ-1 were 3.6\% and $1.5 \%$ of the original no-fatigue compressive bearing capacity, respectively. Though the cyclic loading levels in this test could not be further improved due to the limitation of the loading apparatuses, the composite cross arms showed the gradual degradation behavior under fatigue loading, reflecting the fact that the accumulated damage of GFRP cannot be neglected in the design period. Moreover, due to the anisotropy of the composite material and discrete production process, except for the GZ-3 and GZ-4, the ultimate bearing capacity of specimens decreased obviously with the increase in fatigue loading amplitude.

\section{Fatigue Life Prediction Based on Residual Strength Theory}

The fatigue test, especially for high-cycle fatigue experiment, is time-consuming and costly. There is no accurate guarantee for researchers to make every specimen produce the visual fatigue failure under the preset loading schemes. How to assess the fatigue cumulative damage and to predict the fatigue life of the full-scale components under the finite loading cycles is a practical problem needed to be solved urgently.

The residual strength is one of the most important properties of composite materials under the fatigue loading and is the basis of cumulative damage assessment and fatigue life prediction $[8,9]$. In GFRP, fatigue damage initiates and propagates during cyclic loading, where several types of damage may exist physically at one time or another which in addition may be different during different periods. Certainly, these damages will affect the macroscopic mechanical properties of the material, such as strength or stiffness. Considering the requirement that the parameters should be measured easily, it is assumed for the definition of the cumulative damage model that the strength loss can be used as a metric to evaluate fatigue damage phenomenologically. In this part, the residual strength theory can be applied to assess the fatigue cumulative damage and to predict the fatigue life under finite loading cycles.

4.1. Residual Strength Theory. In the earlier literatures, some analyses and experiments on the residual strength of polymeric composite materials have been carried out based on materials level [8-10, 26, 30-33]. To evaluate the fatigue damage, it must define the damage extent caused by one single loading cycle. Commonly, the Palmgren-Miner rule (P-M rule) defines the damage caused by one single loading cycle while $\Delta D=1 / N_{\mathrm{f}}$, where $N_{\mathrm{f}}$ is the fatigue life under the applied loading, while the damage accumulates linearly until the critical value of 1 is reached. The damage develops unevenly during the cyclic loading, so the cumulative 


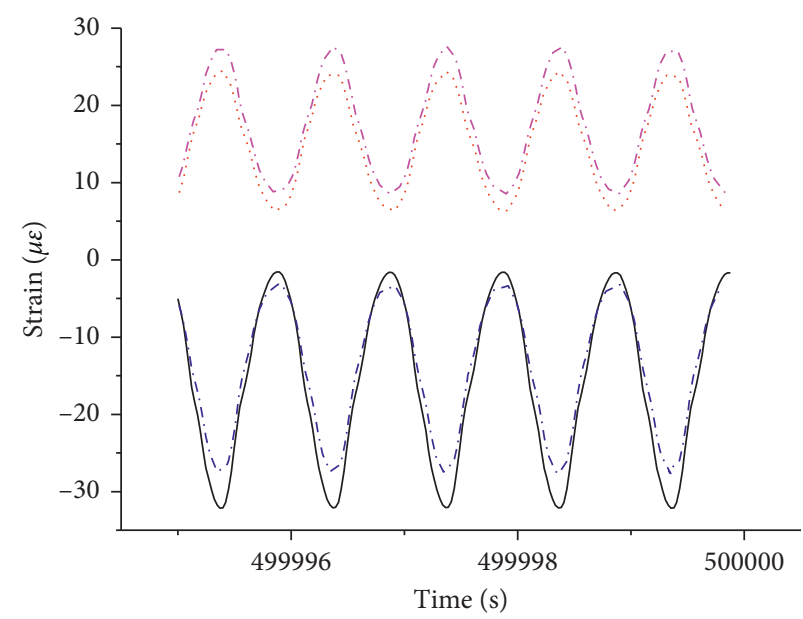

$2-1$

$-\cdot-\cdot 3-1$

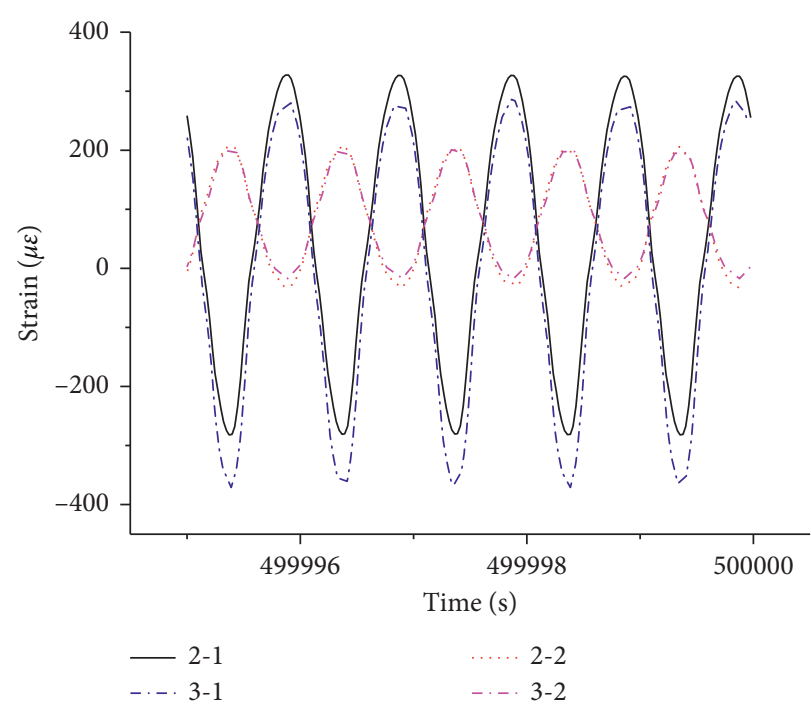

(b)

(a)

FIgure 7: Dynamic strain of composite material: (a) GZ-1; (b) GZ-6.

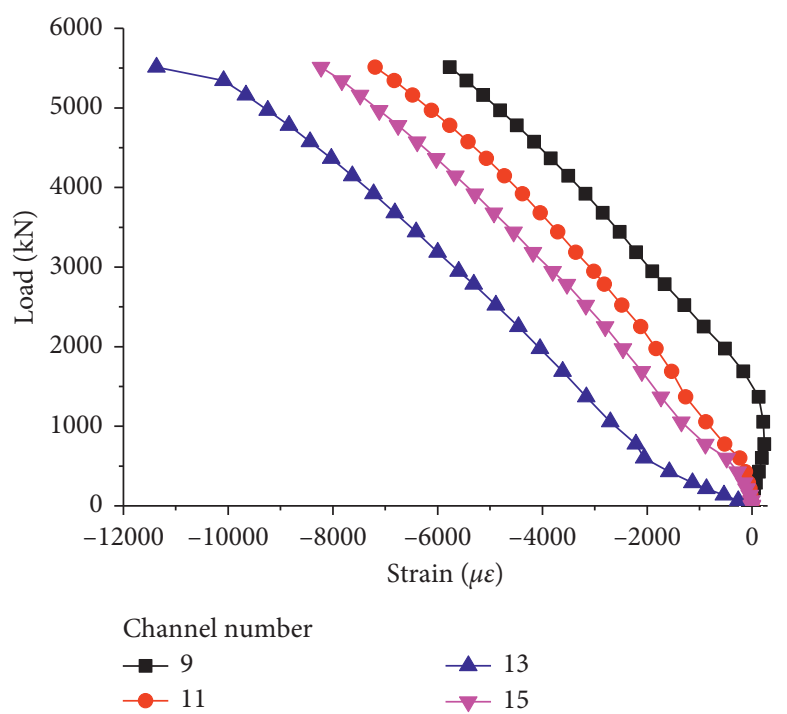

(a)

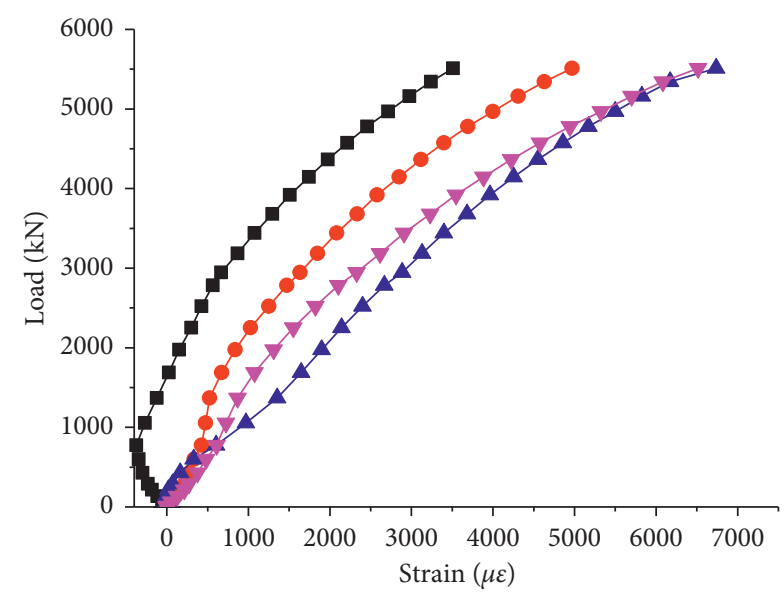

Channel number

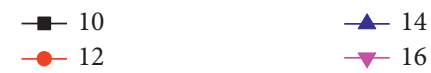

(b)

FIGURE 8: Static strain at the first row of the composite material section of GZ-6: (a) longitudinal load-strain curves; (b) circumferential loadstrain curves.

damage should reflect the variety of stress-strain state under different loading history. In this part, the cumulative fatigue damage can be defined by the following equation $[8,11]$ :

$$
\Delta D_{n}=A[R(n-1)-R(n)],
$$

where $\Delta D$ is the cumulative damage value, $R(n)$ is the residual ultimate bearing capacity after the $n$th fatigue loading cycle, and $A$ is a proportionality coefficient. Different loading cycles lead to different residual ultimate bearing capacities. So there is $\Delta D_{i} \neq \Delta D_{j}(i \neq j)$ apparently, which reflects the damage developing unevenly. As for $A$ in (1), if the applied fatigue spectrum is the constant amplitude, the specimen will fall when the cycle number is equal to the fatigue life $N_{\mathrm{f}}$, and $A$ can be generally derived by the maximum cumulative damage value $D_{\mathrm{cr}}=1$ [11] as follows:

$$
\begin{aligned}
D_{\mathrm{cr}} & =\sum_{i=1}^{N_{\mathrm{f}}} A[R(i-1)-R(i)]=A\left[R(0)-R\left(N_{\mathrm{f}}\right)\right] \\
& =A\left[R(0)-S_{\mathrm{m}}\right] .
\end{aligned}
$$

Hence, 


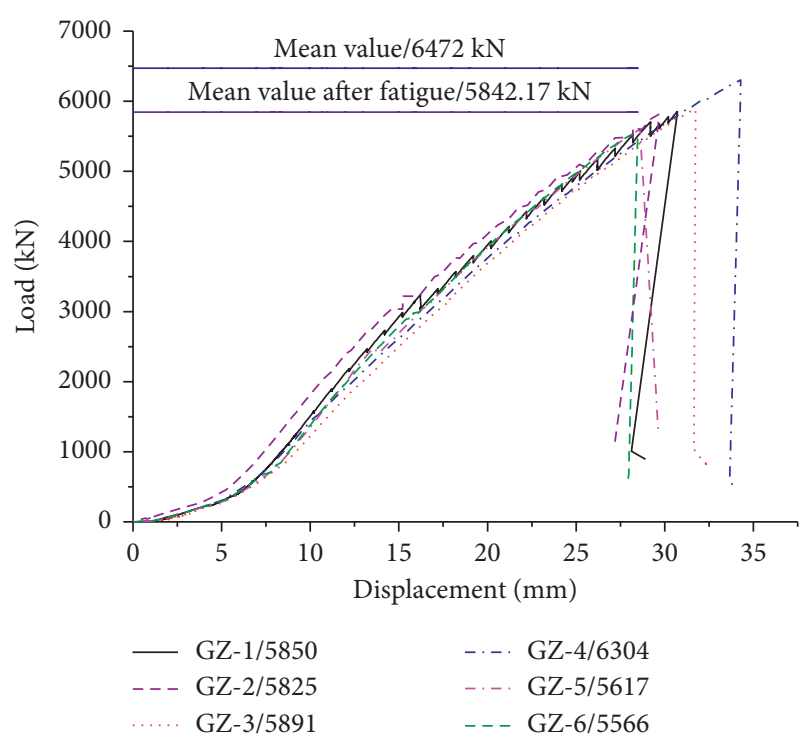

Figure 9: Analysis of ultimate bearing capacity after fatigue.

$$
A=\frac{1}{R(0)-S_{\mathrm{m}}},
$$

where $S_{\mathrm{m}}$ is the peak fatigue load.

In this paper, residual ultimate bearing capacity of the specimens after the fatigue test was obtained in the form of axial compressive ultimate bearing capacity, and the residual strength of specimens after $n$th loading cycle can be modified and expressed in (4) and (5) based on the existing theories $[9,30,34,35]$ :

$$
\begin{aligned}
R(n) & =R(0)-\left[R(0)-S_{\mathrm{m}}\right] f\left(\frac{n}{N_{\mathrm{f}}}\right), \\
f\left(\frac{n}{N_{\mathrm{f}}}\right) & =\left(\frac{n}{N_{\mathrm{f}}}\right)^{v} .
\end{aligned}
$$

The variety of residual strength shown in (4) and (5) can be depicted in Figure 10; it indicates that, at the beginning of the loading, the residual strength decreases rather quickly, which is mainly related to the abrupt forming of small cracks; then, the residual strength decreases moderately and evenly, which is mainly due to the slow development of the cumulative damage; near the fatigue life $N_{\mathrm{f}}$, there is a sudden "sudden death" behavior which demonstrates that the specimen unexpectedly suffers from the complete fatigue failure $[11,34]$.

The factor $v$ in (5) is a degradation parameter that can be determined by energy dissipation in this paper, for which it can be defined as follows:

$$
v=\frac{E_{\text {end }}}{E_{\mathrm{m}}},
$$

where $E_{\text {end }}$ is the energy dissipation value of the final cycle under the fatigue load and $E_{\mathrm{m}}$ is the maximum value of energy dissipation in the fatigue loading history. In this paper, the parameter $v$, depicting the degraded behavior under cyclic fatigue loads through the dissipated energy, is determined by the experimental data. The definition about the parameter $v$,

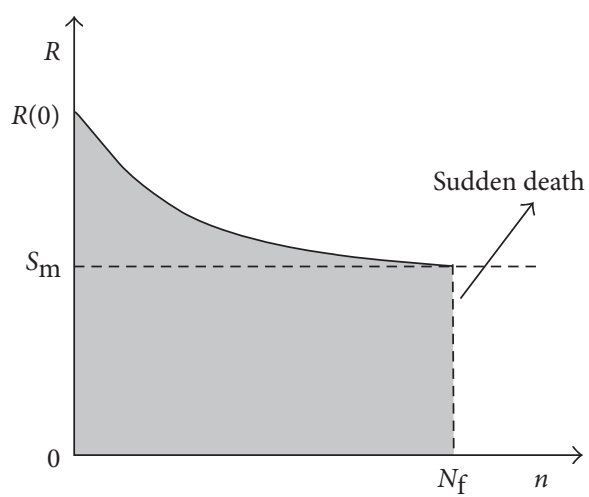

Figure 10: The residual strength model.

specific in physical meaning, is totally different from the other empirical coefficients gained by parameter fitting and can be precisely applied to predict fatigue life.

4.2. Cumulative Damage Evaluation. In this part, the cumulative damage values were evaluated based on the aforementioned modified residual strength theory. Figure 11 shows the cumulative damage assessment for all specimens compared to the intuitive residual strength method based on the continuum damage mechanics, which can be obviously depicted as follows:

$$
\omega=\frac{R(0)-R(n)}{R(0)}=1-\frac{R(n)}{R(0)}
$$

where $\omega$ is the continuum cumulative damage value. The range is $0 \leq \omega \leq 1$ while $\omega=0$ demonstrates no damage phenomenon and $\omega=1$ displays complete failure.

Figure 11 reveals the fact that the damage assessments of two methods agree reasonably well. The cumulative damage values of the intuitive method are slightly smaller because it does not take the different fatigue stress amplitudes into consideration. The verification shows that the modified model, based on the residual strength theory, can be utilized to calculate the cumulative damage values at the component level and also can provide the basic references for the follow-up fatigue life prediction. In Figure 11, except for the large divergence in the cumulative damage value of GZ-4 due to the anisotropy of the composite material and discrete production process, overall the cumulative damage values amplify with the increase in fatigue loads.

4.3. Fatigue Life Prediction. Table 3 provides the fatigue life prediction results of the specimens based on the macroscopic residual bearing capacity. Meanwhile, assuming a specimen GZ-7 by taking the average residual ultimate bearing capacity of $5842.17 \mathrm{kN}$ into consideration, the most unfavorable loading condition 5 was used to predict the mean fatigue life. It should be noted that the original nofatigue compressive bearing capacity and residual bearing capacity after fatigue loading of the vested specimen cannot be obtained synchronously; thus, in this study, the fatigue life prediction was conducted based on the original average 


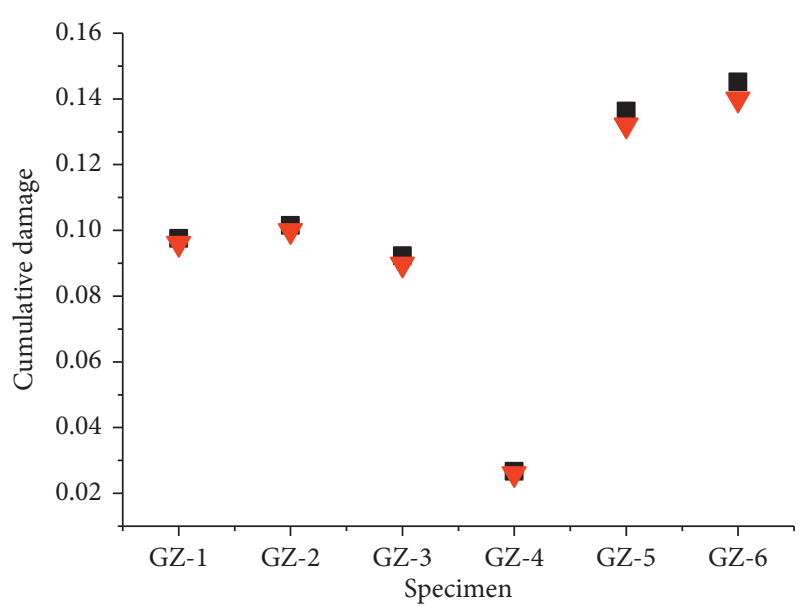

Modified model

Intuitive method

FIGURE 11: Cumulative damage evaluation.

TABle 3: Fatigue life prediction.

\begin{tabular}{lccccc}
\hline Specimen & Loading condition & Cycles & Parameter, $v$ & Residual ultimate bearing capacity $(\mathrm{kN})$ & Fatigue life prediction \\
\hline GZ-1 & 1 & 500,000 & 0.880 & 5,850 & $7,037,400$ \\
GZ-2 & 1 & 500,000 & 0.891 & 5,825 & $6,516,700$ \\
GZ-3 & 2 & 500,000 & 0.983 & 5,891 & $5,643,500$ \\
GZ-4 & 3 & 500,000 & 0.932 & 6,304 & $24,397,000$ \\
GZ-5 & 4 & 500,000 & 0.981 & 5,617 & $3,812,200$ \\
GZ-6 & 5 & 500,000 & 0.979 & 5,566 & $3,590,400$ \\
GZ-7 & 5 & 500,000 & 0.941 & $5,842.17$ & $5,721,700$ \\
\hline
\end{tabular}

compressive bearing capacity of the composite cross arms, where the statistical variation of the composite materials due to the anisotropy was not considered.

The results in Table 3 show that the fatigue life of the GZ-6 specimen, having a cyclic loading level of $3.6 \%$ compared to the original average no-fatigue compressive bearing capacity, is still more than 3.5 million cycles under the most adverse loading condition 5, and because of the anisotropy of the composite material, the fatigue life of the GZ-4 specimen with a cyclic loading level of $2.8 \%$ is higher than other specimens. Moreover, from GZ-1 to GZ-6 except for GZ-4, the predicted fatigue lives decrease apparently with the increase in fatigue loads. The average fatigue life (cyclic loading level 3.6\%) predicted by the average residual ultimate bearing capacity is more than 5.5 million cycles, indicating that the GFRP composite cross arms can resist the multimillion fatigue loads caused by the windinduced vibrations of 1.3 times of the ultimate windy condition $(30 \mathrm{~m} / \mathrm{s})$. The overall prediction result shows that the GFRP-steel sleeve composite cross arms can demonstrate high level of safety redundancy on antifatigue performance and can be expected for wide application in transmission towers.

\section{Conclusions}

In this paper, a total of six GFRP-steel sleeve composite cross arms were subjected to 500 thousand cyclic loads to examine the fatigue performance. After the test, the ultimate bearing capacity of the specimens without significant fatigue failure was evaluated to derive the residual bearing capacity. The conclusions are as follows:

(1) The GFRP-steel sleeve composite cross arms can demonstrate the favourable antifatigue performance under practical loading conditions. Although the load-displacement-time curve shows that there is no apparent degradation phenomenon, the energy dissipation analysis reveals the slow cumulative fatigue damage process.

(2) The dynamic strain of the specimens is tiny, and overall the residual ultimate bearing capacity after fatigue loading decreases gradually with the increase in fatigue loads. All specimens can display the reasonable elastic working state before reaching the ultimate limit state of bearing capacity.

(3) Utilizing the residual ultimate bearing capacity, a modified residual strength model based on the 
component level is presented to evaluate the $\mathrm{cu}$ mulative fatigue damage and to predict the fatigue life. After 500 thousand cycles of fatigue loads, the GFRP cross arms can still perform ideal fatigue life accompanied by the different cumulative fatigue damages to some extent.

In summary, the new type GFRP-steel sleeve composite cross arms can demonstrate the high level of safety redundancy on the antifatigue performance and can be expected for the wide application in power transmission towers.

\section{Data Availability}

The data used to support the findings of this study are available from the corresponding author upon request.

\section{Conflicts of Interest}

The authors declare that they have no conflicts of interest.

\section{Acknowledgments}

The research described in this paper was financially supported by the State Grid Corporation of China (SGTYHT/15-JS197), which is gratefully acknowledged. The authors are also grateful to everyone who participated in this research for their assistance during the experimental program.

\section{References}

[1] K. Fujikake, S. Mindess, and H. Xu, "Analytical model for concrete confined with fiber reinforced polymer composite," Journal of Composites for Construction, vol. 8, no. 4, pp. 341-351, 2004.

[2] B. Saboori and S. M. R. Khalili, "Static analysis of tapered FRP transmission poles using finite element method," Finite Elements in Analysis and Design, vol. 47, no. 3, pp. 247-255, 2011.

[3] Y. Momomura, H. Marukawa, T. Okamura, E. Hongo, and T. Ohkuka, "Full-scale measurements of wind-induced vibration of a transmission line system in a mountainous area," Journal of Wind Engineering and Industrial Aerodynamics, vol. 72, pp. 241-252, 1997.

[4] P. Zhang, L. Ren, H. Li, Z. Jia, and T. Jiang, "Control of windinduced vibration of transmission tower-line system by using a spring pendulum," Mathematical Problems in Engineering, vol. 2015, Article ID 671632, 10 pages, 2015.

[5] Z. Hashin and A. Rotem, "A fatigue failure criterion for fiber reinforced materials," Journal of Composite Materials, vol. 7, no. 4, pp. 448-464, 1973.

[6] R. Talreja, "Fatigue reliability under multiple-amplitude loads," Engineering Fracture Mechanics, vol. 11, no. 4, pp. 839-849, 1979.

[7] R. Talreja, "Fatigue of composite materials: damage mechanisms and fatigue-life diagrams," Proceedings of the Royal Society A: Mathematical, Physical and Engineering Sciences, vol. 378, no. 1775, pp. 461-475, 1981.

[8] Z. Hashin, "Cumulative damage theory for composite materials: residual life and residual strength methods," Composites Science and Technology, vol. 23, no. 1, pp. 1-19, 1985.

[9] J. N. Yang, L. J. Lee, and D. Y. Sheu, "Modulus reduction and fatigue damage of matrix dominated composite laminates," Composite Structures, vol. 21, no. 2, pp. 91-100, 1992.
[10] S. Subramanian, K. L. Reifsnider, and W. W. Stinchcomb, “A cumulative damage model to predict the fatigue life of composite laminates including the effect of a fibre-matrix interphase," International Journal of Fatigue, vol. 17, no. 5, pp. 343-351, 1995.

[11] W. X. Yao and N. Himmel, "A new cumulative fatigue damage model for fibre-reinforced plastics," Composites Science and Technology, vol. 60, no. 1, pp. 59-64, 2000.

[12] M. M. Shokrieh and F. Taheri-Behrooz, "A unified fatigue life model based on energy method," Composite Structures, vol. 75, no. 1-4, pp. 444-450, 2006.

[13] A. Varvani-Farahani, H. Haftchenari, and M. Panbechi, "A fatigue damage parameter for life assessment of off-axis unidirectional GRP composites," Journal of Composite Materials, vol. 40, no. 18, pp. 1659-1670, 2006.

[14] E. N. Eliopoulos and T. P. Philippidis, "A progressive damage simulation algorithm for GFRP composites under cyclic loading. Part I: material constitutive model," Composites Science and Technology, vol. 71, no. 5, pp. 742-749, 2011.

[15] Y. H. Huh, D. J. Kim, and Y. S. Lee, "Effect of stress ratio on fatigue life of GFRP composites for WT blade," Journal of Mechanical Science and Technology, vol. 26, no. 7, pp. 21172120, 2012.

[16] X. S. Sun, A. Haris, V. B. C. Tan, T. E. Tay, S. Narasimalu, and C. N. Della, "A multi-axial fatigue model for fiber-reinforced composite laminates based on Puck's criterion," Journal of Composite Materials, vol. 46, no. 4, pp. 449-469, 2012.

[17] M. Abo-Elkhier, A. A. Hamada, and A. B. El-Deen, "Prediction of fatigue life of glass fiber reinforced polyester composites using modal testing," International Journal of Fatigue, vol. 69, pp. 28-35, 2014.

[18] S. Mortazavian and A. Fatemi, "Fatigue behavior and modeling of short fiber reinforced polymer composites including anisotropy and temperature effects," International Journal of Fatigue, vol. 77, pp. 12-27, 2015.

[19] S. Stelzer, G. Pinter, and A. J. Brunner, "Comparison of quasistatic and cyclic fatigue delamination resistance of carbon fiber reinforced polymer-matrix laminates under different mode loading," Procedia Materials Science, vol. 3, pp. 10871092, 2014.

[20] J. Brunbauer, H. Stadler, and G. Pinter, "Mechanical properties, fatigue damage and microstructure of carbon/epoxy laminates depending on fibre volume content," International Journal of Fatigue, vol. 70, pp. 85-92, 2015.

[21] D. Vasiukov, S. Panier, and A. Hachemi, "Direct method for life prediction of fiber reinforced polymer composites based on kinematic of damage potential," International Journal of Fatigue, vol. 70, pp. 289-296, 2015.

[22] W. Zhang, Z. Zhou, B. Zhang, and S. Zhao, "A phenomenological fatigue life prediction model of glass fiber reinforced polymer composites," Materials and Design, vol. 66, pp. 7781, 2015.

[23] E. Belmonte, M. D. Monte, C. Hoffmann, and M. Quaresimin, "Damage mechanisms in a short glass fiber reinforced polyamide under fatigue loading," International Journal of Fatigue, vol. 94, pp. 145-157, 2017.

[24] A. J. Brunner, S. Stelzer, G. Pinter, and G. P. Terrasi, "Cyclic fatigue delamination of carbon fiber-reinforced polymermatrix composites: data analysis and design considerations," International Journal of Fatigue, vol. 83, pp. 293-299, 2016.

[25] Z. Liu, P. Li, N. Srikanth, T. Liu, and G. B. Chai, "Quantification of flexural fatigue life and 3D damage in carbon fibre 
reinforced polymer laminates," Composites Part A: Applied Science and Manufacturing, vol. 90, pp. 778-785, 2016.

[26] J. N. Yang and M. D. Liu, "Residual strength degradation model and theory of periodic proof tests for graphite/epoxy laminates," Journal of Composite Materials, vol. 11, no. 2, pp. 176-203, 1977.

[27] F. Y. Liao, L. H. Han, and Z. Tao, "Behavior of composite joints with concrete encased CFST columns under cyclic loading: experiments," Engineering Structures, vol. 59, pp. 745-764, 2014.

[28] T. Zhou, Z. Chen, and H. Liu, "Seismic behavior of special shaped column composed of concrete filled steel tubes," Journal of Constructional Steel Research, vol. 75, pp. 131-141, 2012.

[29] S. L. McCabe and W. J. Hall, "Assessment of seismic structural damage," Journal of Structural Engineering, vol. 115, no. 9, pp. 2166-2183, 1989.

[30] C. C. Pei and R. Croman, "Residual strength in fatigue based on the strength-life equal rank assumption," Journal of Composite Materials, vol. 12, pp. 177-194, 1978.

[31] A. Haque, J. Krishnagopalan, and S. Jeelani, "Fatigue damage in laminated composites," Journal of Reinforced Plastics and Composites, vol. 12, no. 10, pp. 1058-1069, 1993.

[32] B. Liu and L. B. Lessard, "Fatique and damage-tolerance analysis of composite laminates: stiffness loss, damagemodelling, and life prediction," Composites Science and Technology, vol. 51, no. 1, pp. 43-51, 1994.

[33] J. R. Schaff and B. D. Davidson, "Life prediction methodology for composite structures. Part I-constant amplitude and twostress level fatigue," Journal of Composite Materials, vol. 31, no. 2, pp. 128-157, 1997.

[34] L. J. Broutman and S. Sahu, "A new theory to predict cumulative fatigue damage in fiberglass reinforced plastics," in Proceedings of the Second Conference on Composite Materials: Testing and Design, ASTM STP 497, pp. 170-188, Anaheim, CA, USA, April 1971.

[35] A. Charewicz and I. M. Daniel, "Damage mechanisms and accumulation in graphite/epoxy laminates," in Proceedings of the Composite Materials: Fatigue and Fracture, ASTM STP 907, pp. 97-274, Dallas, TX, USA, 1986. 


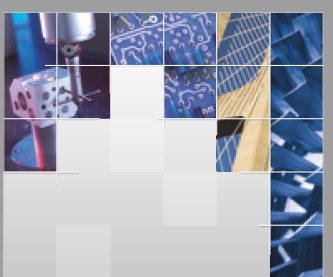

\section{Enfincering}
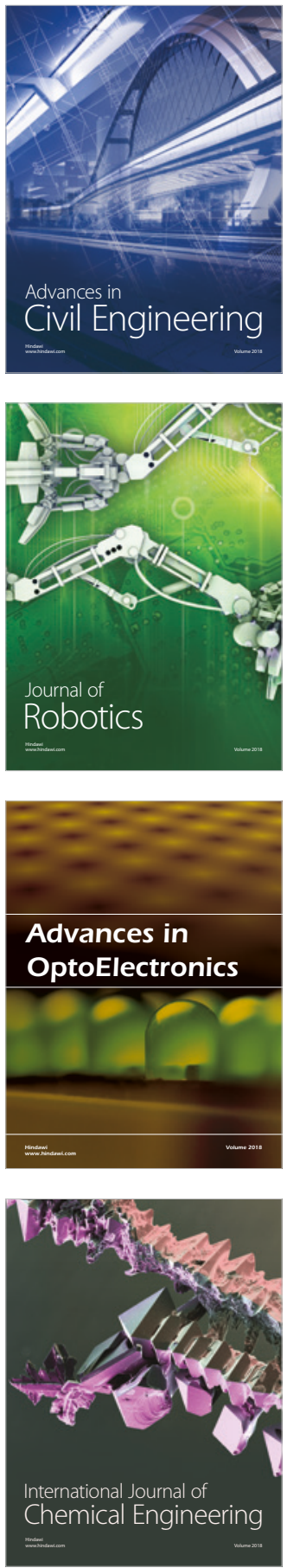

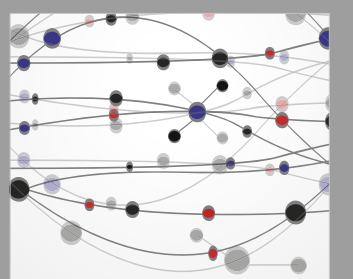

\section{Rotating \\ Machinery}

The Scientific World Journal

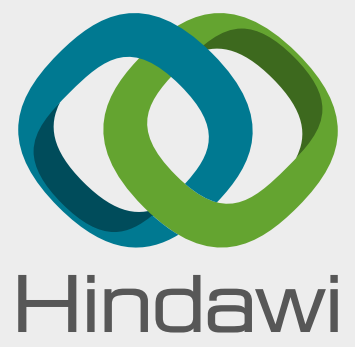

Submit your manuscripts at

www.hindawi.com
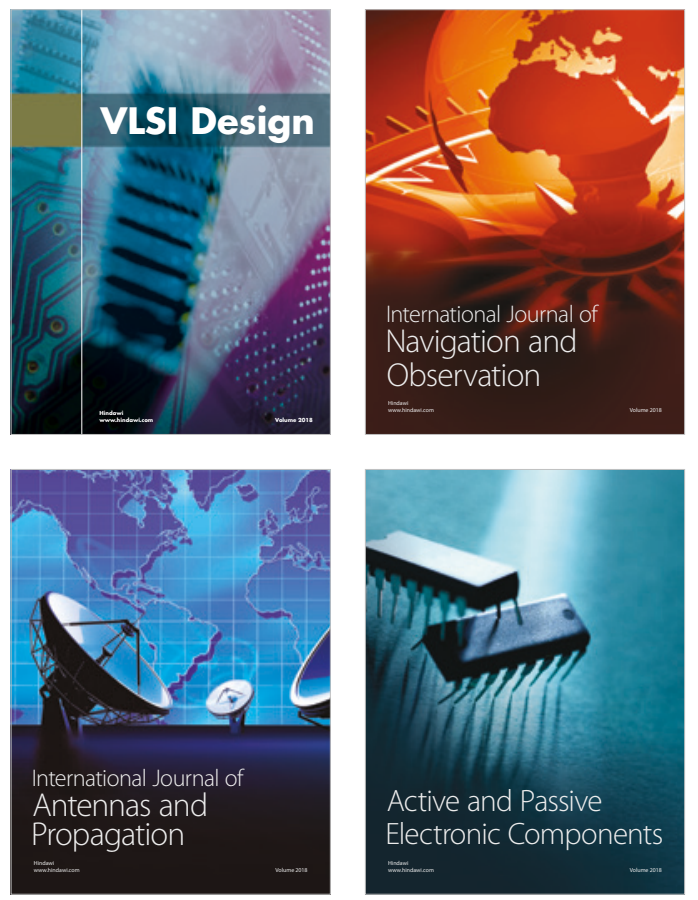
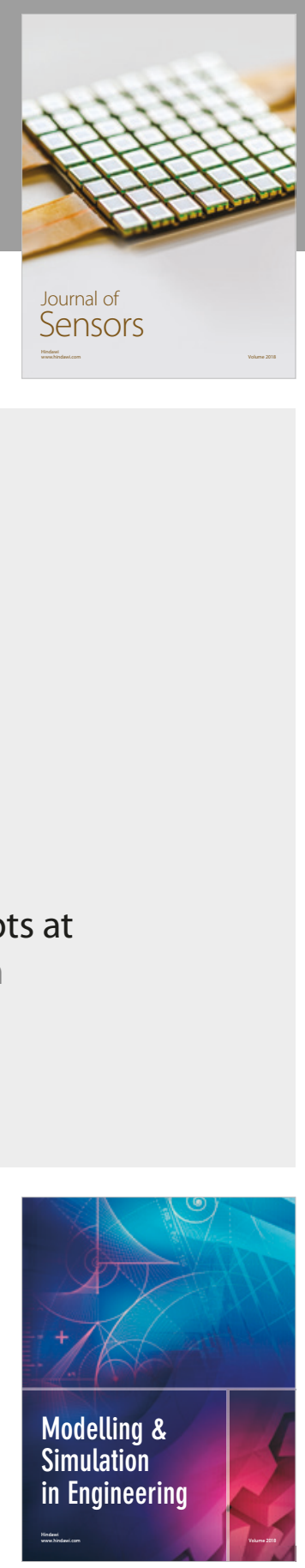

\section{Advances \\ Multimedia}
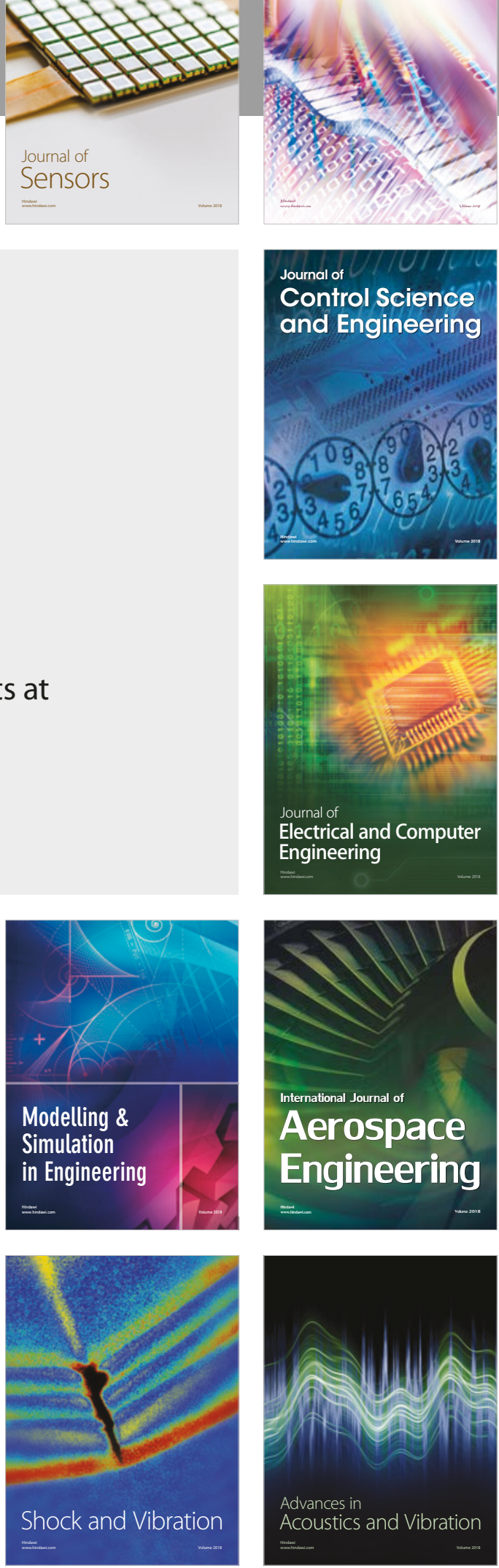